\title{
Effect of Primary Health Care Orientation on Chronic Care Management
}

\author{
Julie A. Schmittdiel, $P b D^{1}$ \\ Stephen M. Shortell, $P b D^{2}$ \\ Thomas G. Rundall, $P b D^{2}$ \\ Thomas Bodenheimer, $M D^{3}$ \\ Joe V. Selby, MD, MPH \\ 'Kaiser Permanente Northern California \\ Division of Research, Oakland, Calif \\ ${ }^{2}$ School of Public Health, University \\ of California, Berkeley, Calif \\ ${ }^{3}$ Department of Family and Community \\ Medicine, University of California, San \\ Francisco, Calif
}

sit

MORE ONLINE

www.annfammed.org
Conflicts of interest: none reported

\section{CORRESPONDING AUTHOR}

Julie Schmittdiel, PhD

Kaiser Permanente Northern California

Division of Research

2000 Broadway

Oakland, CA 94612

Julie.A.Schmittdiel@kp.org

\begin{abstract}
PURPOSE It has been suggested that the best way to improve chronic illness care is through a redesign of primary care emphasizing comprehensive, coordinated care as espoused by the Chronic Care Model (CCM). This study examined the relationship between primary care orientation and the implementation of the CCM in physician organizations.
\end{abstract}

METHODS The relationship between measures of primary care orientation and the CCM was examined in a sample of 957 physician organizations from the National Study of Physician Organizations, a cross-sectional telephone survey of all US medical groups and independent practice associations with 20 or more physicians (response rate, 70\%).

RESULTS After adjusting for potential confounders, 6 of 8 measures of primary care orientation were associated with physician organizations' adoption of 11 elements of CCM chronic care management. These 6 measures were severity of chronic illness treated in primary care, health promotion activity, health education activity, any accepted financial risk for hospitalization, required reporting, and presence of an electronic standardized problem list. Presence of an electronic medical record and the 5-year primary care physician turnover rate were not associated.

CONCLUSIONS Organizations that have adopted 6 core attributes of primary care, representing comprehensive health service delivery and a commitment to overall patient health, appear to use more chronic care management practices. Policy makers and other stakeholders may wish to focus on creating an improved primary care home in their quest to close the "quality chasm" in chronic illness care.

Ann Fam Med 2006;4:117-123. DOI: 10.1370/afm.520.

\section{INTRODUCTION}

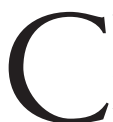
hronic conditions are the leading cause of illness, death, and disability in the United States each year. ${ }^{1}$ Nationwide, more than 100 million people live with a chronic illness, and their care comprises three quarters of annual health care expenditures., ${ }^{2,3}$ Many patients with chronic illness do not receive the medical care appropriate for their condition, however. ${ }^{1,4-6}$

A growing body of literature argues that an effective approach to meeting the needs of chronically ill patients is to improve the delivery of primary care, ${ }^{7-10}$ stating that high-quality chronic illness care is difficult to achieve in primary care settings when the system centers on treating acute illnesses. Chronic illness care could be improved, it is believed, if delivery systems adopt a primary health care orientation emphasizing comprehensiveness of care and the overall health of the patient. ${ }^{7-12}$

The link between greater primary health care orientation and improved chronic illness care at the organizational level remains hypothetical, however. There is currently no work that examines the empirical relationship between the key theoretical concepts of primary health care and models of quality chronic illness care. 
The purpose of this study was to determine whether physician organizations with a high degree of primary health care orientation also have a high degree of chronic illness care management as evidenced by their implementation of the Chronic Care Model (CCM).

\section{METHODS}

The CCM outlines 6 organization-level dimensions that are considered integral to providing optimal care to patients with chronic illness ${ }^{7,13-16}$ :

1. Organization of the health care delivery system: The organization is structured to focus on chronic illness care, and leadership makes improving this care a priority.

2. Community linkages: The organization links to community agencies that assist patients with chronic illness and has referral systems to such agencies.

3. Self-management support for patients: Organizations encourage patients to play an active role in their own health by providing programs that encourage lifestyle changes and develop competency in illness management.

4. Decision support for physicians: Organizations provide their physicians with evidence-based guidelines for treating chronically ill patients, integrate guidelines into patient care, and provide primary care physicians access to specialist expertise.

5. Delivery system design: The organization's delivery of care provides continuity between primary and specialty care, and allows for team-based, nonurgent chronic care visits.

6. Clinical information systems: The organization has clinical information systems with individual- and population-level information on chronically ill patients, and uses them to give physicians performance feedback and care reminders.

Evidence suggests that the application of these CCM principles to health care systems leads to better outcomes for patients with chronic illness. ${ }^{16-19}$

Primary health care focuses on overall health and preventive care, ${ }^{11,12}$ and contrasts with traditional medical care models that emphasize diagnosing and curing acute illnesses. This model is based on 5 principles:

1. First contact: Primary care physicians should be a patient's first contact with the health care system for any problem and the window to the use of specialists.

2. Continuity/longitudinality: The relationship between the primary care physician and patient should be long term and consistent over time.

3. Comprehensiveness: Primary care should provide a wide range of preventive and acute care services to meet a large proportion of patients' medical needs.

4. Coordination: Primary care systems should be able to coordinate care across physicians, ideally using electronic information systems.

5. Accountability: Primary care physicians should be held accountable for patients' overall health and medical outcomes.

Studies of the primary health care principles strongly support the assertion that health care systems based on the principles of primary health care deliver high-quality, cost-effective care to patients. ${ }^{20-28}$

The CCM and primary health care principles were developed separately; however, similarities in their constructs suggest that physician organizations that apply the concepts of primary health care to their care delivery may also be committed to the CCM. We carried out an empirical test of this hypothesis.

\section{Data Source}

Data were obtained from the National Study of Physician Organizations and the Management of Chronic Illness (NSPO). ${ }^{5}$ This study was designed to measure the organizational characteristics and care management processes among all US medical groups and independent practice associations (IPAs) with 20 or more physicians treating patients with chronic illness. The NSPO survey was conducted by the National Opinion Research Center via telephone from September 2000 to September 2001. A questionnaire, the survey instrument, was administered to the chief executive officer, president, or medical director of each organization. Of the 1,587 physician organizations in the census, 1,104 completed the questionnaire, for a response rate of $70 \%$. Further information is available elsewhere (http:// nspo.berkeley.edu).

This analysis was limited to the 957 responding physician organizations with primary care physicians who reported caring for patients with diabetes, asthma, congestive heart failure (CHF), or depression, or some combination thereof. Our study was granted exemption by the University of California at Berkeley Committee for the Protection of Human Subjects.

\section{Measures}

Implementation of CCM

Implementation of the CCM was measured using a set of questions (available online-only in the Supplemental Appendix at http://www.annfammed.org/cgi/content/full/4/2/117/DC1) designed to correspond to $5 \mathrm{CCM}$ dimensions. ${ }^{5}$ Two questions asked the organization about links to community services for chronically ill patients and assessed the existence of written agreements and referral systems to community programs. Two questions asked about assessment of self-management needs and provision of self-management support to patients with chronic illness. Two 
questions asked about the decision support offered to physicians through use of guidelines and access to specialists. Three questions focused on the design of delivery systems and assessed the use of planned visits, multiprovider visits, and case managers. Two questions asked about the information systems available to physicians through feedback reports and to patients through Internet access to their physicians.

These 11 questions combined comprise the Chronic Care Model Index (CCMI, Cronbach $\alpha=.77$ ). One CCM dimension, the organization of the health care delivery system, was not represented because of the difficulty in obtaining reliable data on this dimension using the abbreviated survey format available.

\section{Primary Health Care Orientation}

The primary health care measures used in this analysis were adapted to the parameters gathered by the NSPO study (Supplemental Appendix), which although not designed to measure primary health care orientation, offers many of the elements suggested in the primary health care literature. ${ }^{11,12}$

Recommended measures of the comprehensiveness of primary care examine the presence of programs for illness prevention and the range of services provided to patients. ${ }^{11}$ The NSPO combined 8 questions regarding the presence of specific health promotion programs (nutrition, smoking cessation, weight loss, prenatal education, health risk assessment, sexually transmitted disease prevention, stress management, and substance abuse) into a health promotions index (Cronbach $\alpha=$ $.85)$. Four questions regarding the presence of health education programs for asthma, $\mathrm{CHF}$, depression, and diabetes were combined into a health education index (Cronbach $\alpha=.81$ ). A final measure of comprehensiveness comes from the combination of 4 questions asking whether the physician organization treats severe asthma, depression, $\mathrm{CHF}$, and diabetes in primary care (vs specialty care) into a 4-point index of severity of illness treated in primary care (Cronbach $\alpha=.64$ ).

The primary health care principle of coordination outlines care that incorporates information technology to provide an electronic medical record and standardized problem list for each patient. ${ }^{11,12}$ While capabilities of this technology do not completely define primary health care coordination, they are considered an essential element for coordinating care across physicians and settings. ${ }^{11,12}$ The NSPO questionnaire asked 2 yes/no questions on whether organizations have these technologies.

The NSPO survey yielded 2 accountability measures for primary care. The first determined the percentage of health maintenance organization patients for which the organization and point-of-service patients accepted some financial risk for hospitalization costs. The second used 4 questions asking whether the organization was required to report any data on patient satisfaction results, quality improvement projects, outcomes, or HEDIS (Health Plan Employer Data and Information Set) to outside organizations; the 4 questions were combined into an outside reporting index (Cronbach $\alpha=.89$ ).

The mean length of time a patient is with a primary care physician, the recommended measure for continuity/longitudinality of care, ${ }^{11}$ could not be used because no patient-level data were available from the NSPO. As a proxy, we used the turnover rate for primary care physicians within each organization during the last 5 years. The dimension of first contact was not measured in the NSPO.

\section{Statistical Analysis}

We used a linear ordinary least squares regression model to estimate the CCMI using the 8 measures of primary health care orientation and adjusting for 9 control variables: organization age, number of physicians, number of clinics, ownership type, region, organizational type, county-level health maintenance organization penetration ${ }^{29}$ (defined as the number of people enrolled in health maintenance organizations in a physician organization's county divided by the county population) practice setting, and log of total capital per physician. Statistical analysis was done using SAS version 8.2 (SAS Institute, Cary, NC).

\section{RESULTS}

Of the 957 physician organizations, approximately two thirds (621) were medical groups, and the remaining ones (336) were IPAs. The general characteristics of these organizations are described in Table 1.

The percentage of physician organizations that reported having implemented each individual CCM element ranged from a high of $64.3 \%$ (for the ability to integrate specialist expertise into chronic illness care) to a low of $20.9 \%$ (for the presence of agreements with community services agencies providing resources for chronically ill patients) (Table 2). Out of a possible score of 11 , the mean CCMI score across the physician organizations was 4.6. More than 90\% (865) of the physician organizations had implemented at least 1 of the CCM elements, while only $1.3 \%$ (12) reported having implemented all 11 elements.

Table 3 shows the distribution of the variables used to measure primary health care orientation. The mean physician turnover rate in a 5 -year period was $5.7 \%$. Physician organizations scored a mean of 2.4 out of 4 on the health education index and 2.5 out of 8 on the health promotion index. The mean index of severity 


\begin{tabular}{|c|c|}
\hline Characteristic & $\begin{array}{l}\text { Total } \\
(\mathrm{N}=957)\end{array}$ \\
\hline \multicolumn{2}{|l|}{ Organizational type, No. (\%) } \\
\hline Medical group & $621(64.9)$ \\
\hline IPA & $336(35.1)$ \\
\hline \multicolumn{2}{|l|}{ Ownership type, No. (\%) } \\
\hline Hospital/health plan & $376(39.3)$ \\
\hline $\mathrm{MD}$ & $456(47.6)$ \\
\hline Other & $125(13.1)$ \\
\hline \multicolumn{2}{|l|}{ Region, ${ }^{*}$ No. (\%) } \\
\hline East North Central & $169(17.7)$ \\
\hline East South Central & $45(4.7)$ \\
\hline Middle Atlantic & $101(10.6)$ \\
\hline Mountain & $59(6.2)$ \\
\hline Northeast & $58(6.1)$ \\
\hline Pacific & $245(25.6)$ \\
\hline South Atlantic & $118(12.3)$ \\
\hline West North Central & $81(8.4)$ \\
\hline West South Central & $81(8.4)$ \\
\hline \multicolumn{2}{|l|}{ Practice location, No. (\%) } \\
\hline Urban/suburban & $665(69.5)$ \\
\hline Rural/small town & $292(30.5)$ \\
\hline Age of organization, mean (SD), y & $25.7(21.9)$ \\
\hline No. of MDs, mean (SD) & $239.9(424.1)$ \\
\hline No. of clinic sites, mean (SD) & $77.9(266.6)$ \\
\hline County HMO penetration, mean (SD), \% & $33.1(17.2)$ \\
\hline $\begin{array}{l}\text { Physicians who are primary care physicians, } \\
\text { mean (SD), \% }\end{array}$ & $50.9(28.2)$ \\
\hline Capital per MD, log, mean (SD) & $\begin{array}{l}120,706.7 \\
(359,996.0)\end{array}$ \\
\hline \multicolumn{2}{|c|}{$\begin{array}{l}\text { IPA }=\text { independent practice association; } \mathrm{MD}=\text { medical doctor; } \mathrm{HMO}=\text { health } \\
\text { maintenance organization. }\end{array}$} \\
\hline \multicolumn{2}{|c|}{$\begin{array}{l}\text { * As defined in the American Medical Association census (Havlicek PI. Medical } \\
\text { Groups in the US, 1999. Chicago, III: American Medical Association; 1999). }\end{array}$} \\
\hline
\end{tabular}

of chronic illness treated was 0.5 out of 4 . One fifth $(19.6 \%)$ of the physician organizations reported having an electronic medical record; a similar proportion (17.6\%) reported having an electronically available standardized problem list. The mean value for the outside reporting requirements measure was 0.8 out of 4 , while the percentage of physician organizations that accepted any risk for patient hospitalization cost was $42.4 \%$.

Table 4 looks at the relationship between the overall CCMI and each primary health care measure after adjusting for the levels of the other primary health care measures and the control variables. Of the 8 primary health care measures, 6 were significantly and positively related to the CCMI: severity of chronic illness treated in primary care, health promotion activity, health education activity, any accepted financial risk for hospitalization, required reporting, and presence of an electronic standardized problem list. Being a medical group was also significantly related to CCMI, as was larger organizational size.
Table 2. Measures of CCM Implementation Among Physician Organizations

\begin{tabular}{lc}
\hline & $\begin{array}{c}\text { Total } \\
\text { (N = 957) } \\
\text { No. (\%) }\end{array}$ \\
\hline Measure & \\
\hline Community linkages & $200(20.9)$ \\
Q55a: Agreements with community & \\
services agencies & $313(32.7)$ \\
Q55b: Referrals to community agencies & \\
Self-management support & $423(44.2)$ \\
Q56a: Assess self-management needs & $542(56.6)$ \\
Q56b: Self-management programs & \\
Decision support & $499(52.1)$ \\
Q57a: Integrate guidelines into care & $615(64.3)$ \\
Q57b: Integrate specialists into care & \\
Delivery system design & $536(56.0)$ \\
Q58a: Use planned visits & $335(35.0)$ \\
Q58b: Multiple professionals seen in 1 visit & $346(36.2)$ \\
Q58c: Employ case managers & \\
Information systems & \\
Q59a: Written feedback to physicians & $349(36.5)$ \\
Q59b: Internet communication between & $250(26.1)$ \\
physicians and patients & \\
Overall & \\
Use of any CCM element & \\
Use of all 11 CCM elements & \\
CCMI, mean (SD) & \\
\hline CCM = Chronic Care Model; Q = question; ccMI = Chronic Care Model Index. \\
\hline
\end{tabular}

\section{Table 3. Measures of Primary Health Care Orientation Among Physician Organizations}

\begin{tabular}{|c|c|}
\hline Measure & $\begin{array}{c}\text { Total } \\
(\mathbf{N}=957)\end{array}$ \\
\hline \multicolumn{2}{|l|}{ Continuity/longitudinality } \\
\hline $\begin{array}{l}\text { Primary care physician turnover rate over } \\
5 \text { years, mean (SD), \% }\end{array}$ & $5.7(8.4)$ \\
\hline \multicolumn{2}{|l|}{ Comprehensiveness } \\
\hline $\begin{array}{l}\text { Severe chronic illness treated in primary care } \\
\text { index, mean (SD)* }\end{array}$ & $0.5(0.9)$ \\
\hline Health promotions index, mean $(S D)^{\dagger}$ & $2.5(2.6)$ \\
\hline Health education index, mean (SD)* & $2.4(1.5)$ \\
\hline \multicolumn{2}{|l|}{ Coordination } \\
\hline Presence of electronic medical record, No. (\%) & $188(19.6)$ \\
\hline $\begin{array}{l}\text { Presence of electronic standardized problem } \\
\text { list, No. (\%) }\end{array}$ & $168(17.6)$ \\
\hline \multicolumn{2}{|l|}{ Accountability } \\
\hline Required outside reporting index, mean (SD)* & $0.8(1.4)$ \\
\hline $\begin{array}{l}\text { Physician organization accepts any financial risk } \\
\text { for hospital costs, No. (\%) }\end{array}$ & $406(42.4)$ \\
\hline
\end{tabular}

\section{DISCUSSION}

This study is the first empirical test of the relationship between the principles of primary health care orientation and CCM implementation in physician organiza- 
tions. Our analysis strongly supports the existence of a relationship between the primary health care orientation of a physician organization and the organization's implementation of the CCM. Of the 8 primary health care orientation measures, 6 were positively related to CCM implementation at the $P<.05$ level (Table 4 ). The effect sizes were substantial; for example, after adjusting for all other variables, accepting any risk for hospitalization costs was associated with the adoption of more than one half of a CCM element, and the use of each additional health promotion program was associated with the adoption of 0.4 CCM elements.

Medical groups implement more elements of the CCM than do IPAs (Table 4). The literature suggests that medical groups are formed specifically to organize and coordinate patient care, whereas IPAs are primarily organized for contracting and financial purposes. ${ }^{30,31}$ Medical groups may have structural, procedural, and cultural differences from IPAs that lead to their greater use of the CCM.

While organizational size is also significantly related with CCM implementation, the practical effect is small; an increase of 100 physicians is associated with only a 0.07 increase in CCMI. Attempts to examine size as a categorical variable did not demonstrate any statistically significant impact on CCMI.

While this analysis found strong links between this study's measures of primary health care orientation and CCM implementation, the data imply that the level of primary health care orientation is relatively low in US physician organizations (Table 3 ). The use of health promotion and education programs is quite limited, and less than $20 \%$ of physician organizations had electronic medical records or a standardized problem list to coordinate care. Physician organizations had almost no outside reporting requirements, and less than one half were held accountable for outcomes through financial risk for hospitalization.

Our analysis also confirms results from previous studies suggesting a gap between the reference standards of chronic illness care and the level of chronic care management processes provided by physician organizations. ${ }^{4-6}$ On average, fewer than 5 of the 11 items in the CCM were implemented by physician organizations, and only $1.3 \%$ implemented all of the CCM measures (Table 2).

Health policy literature suggests that an effective approach to improving the quality of chronic illness care is through improved primary care delivery. ${ }^{7-10}$ By showing that physician organizations that practice primary health care-oriented medical care also have a greater degree of CCM implementation, this research begins to add empirical justification for creating a primary care home for chronic illness care.
Table 4. Multivariate Linear Regression Analysis Predicting CCMI

\begin{tabular}{|c|c|}
\hline Variable & $\begin{array}{l}\beta \text { Coefficient } \\
\text { (SE) }\end{array}$ \\
\hline \multicolumn{2}{|l|}{ Primary health care orientation measures } \\
\hline \multicolumn{2}{|l|}{ Comprehensiveness } \\
\hline $\begin{array}{l}\text { Severe chronic illness treated in primary } \\
\text { care index* }\end{array}$ & $.24 \S(.09)$ \\
\hline Health promotions index ${ }^{\dagger}$ & $.39^{\circ}(.04)$ \\
\hline Health education index* & $.31^{\top}(.06)$ \\
\hline \multicolumn{2}{|l|}{ Accountability } \\
\hline $\begin{array}{l}\text { Physician organization accepts any financial } \\
\text { risk for hospital costs vs none }\end{array}$ & $.56^{\S}(.18)$ \\
\hline Required outside reporting index* & $.22^{\bullet}(.06)$ \\
\hline \multicolumn{2}{|l|}{ Continuity/longitudinality } \\
\hline $\begin{array}{l}\text { Primary care physician turnover rate over } \\
5 \text { years, } \%\end{array}$ & $-.01(.009)$ \\
\hline \multicolumn{2}{|l|}{ Coordination } \\
\hline Presence of electronic medical record & $.27(.24)$ \\
\hline $\begin{array}{l}\text { Presence of electronic standardized } \\
\text { problems list }\end{array}$ & $.49 \ddagger(.25)$ \\
\hline \multicolumn{2}{|l|}{ Control variables } \\
\hline Urban/suburban vs rural/small town & $.002(.20)$ \\
\hline Age of organization, y & $.005(.004)$ \\
\hline No. of MDs & $.0006^{\S}(.0002)$ \\
\hline No. of clinic sites & $-.0003(.0003)$ \\
\hline \multicolumn{2}{|l|}{ Ownership (vs MD) } \\
\hline Hospital/health plan & $.04(.20)$ \\
\hline Other & $.49(.26)$ \\
\hline Pacific region vs all others & $.39(.21)$ \\
\hline Medical group vs IPA & $1.18^{9}(.24)$ \\
\hline Capital per MD, log & $.005(.02)$ \\
\hline County HMO penetration, \% & $.008(.005)$ \\
\hline \multicolumn{2}{|c|}{$\begin{array}{l}\mathrm{CCMI}=\text { Chronic Care Model Index; } \mathrm{MD}=\text { medical doctor; IPA }=\text { independent } \\
\text { practice association; } \mathrm{HMO}=\text { health maintenance organization. }\end{array}$} \\
\hline \multicolumn{2}{|l|}{ Note: Adjusted $R^{2}=.35$} \\
\hline $\begin{array}{l}\text { * Possible range, } 0 \text { to } 4 . \\
\text { † Possible range, } 0 \text { to } 8 . \\
\text { † } P<.05 \\
\text { § } P<.01 \\
\text { I } P<.001\end{array}$ & \\
\hline
\end{tabular}

\section{Limitations of the Findings}

Data from the NSPO survey are self-reported, organizational leaders may have exaggerated their organization's primary health care focus and use of care management. The level of practices related to care management and primary health care orientation reported by physician organizations was quite low overall, however (Tables 2 and 3); one would expect that if a considerable overreporting bias existed, these levels would be higher. Qualitative interviews conducted as part of the $\mathrm{NSPO}^{32,33}$ also corroborated the survey results. Outside sources of levels of practices related to care management further lend face validity to the NSPO results. One national study found that $55 \%$ of patients were cared for using care management guidelines ${ }^{6}{ }$ this 
number is strikingly similar to the $52.1 \%$ of physician organizations in the NSPO who reported integrating guidelines into care (Table 2).

The NSPO survey was designed to measure care management practices, and the questions used to assess CCM implementation were designed with the assistance of those who developed the model. ${ }^{5}$ The validity of the primary health care orientation measures is less certain, however; the survey was not designed to assess primary health care and offers no way to measure 1 of the 5 concepts, first contact for care. Even so, the NSPO does offer many of the measures suggested in the primary health care literature ${ }^{11,12}$; in particular, the comprehensiveness, coordination, and accountability measures are quite similar to what is available in NSPO One way to examine construct validity is to determine whether the variables in question are associated with other variables in ways we would expect. In this study, comprehensiveness, coordination, and accountability (which have stronger operationalizations) correlated with the CCM, whereas continuity (which had a weak operationalization) did not.

This study focuses on physician organizations with at least 20 medical doctors. These organizations represent a minority of the physicians providing patient care in the United States, which may limit the generalizability of these findings. While it seems likely that smaller organizations have a lesser capacity to implement care management processes ${ }^{5}$ and aspects of primary health care, there is no reason to believe that the relationship between them does not hold in smaller organizations. This is an area for future research.

The NSPO data set is cross-sectional. The finding of a relationship between the primary health care orientation of physician organizations and greater CCM implementation does not mean that one causes the other. Greater primary care orientation may lead to better chronic care management, or organizations with higher levels of chronic care management may orient their primary care systems to facilitate these processes. It could also be that organizations with a focus on overall quality of care, encompassing both chronic and acute care, are more likely to be invested in both primary health care and chronic care management. The finding of an empirical relationship between primary health care orientation and improved chronic care management argues strongly for the compatibility of these 2 sets of concepts, however. Regardless of causality, these findings help make the case that an improved primary care setting for chronic illness care can be a nurturing environment in which to increase the use of practices for chronic illness care management.

Chronic illness places a great burden on health care system resources and has a tremendous negative impact on population health. This research is consistent with many earlier studies in demonstrating the "quality chasm" between the processes of chronic illness care that could be provided by the health care system and those that patients actually receive. This research gives empirical justification for creating a primary care home for chronic illness care, while also showing that we may have a long way to go in creating a US health care system with a focus on primary health care principles. Efforts by physician organizations, payers, and policy makers to increase the primary care orientation of physician organizations may have a positive impact on closing the gap in quality for chronic illness care.

To read or post commentaries in response to this article, see it online at http://www.annfammed.org/cgi/content/full/4/2/117.

Key words: Primary health care; Chronic Care Model; chronic disease; delivery of health care; quality of health care; health services research

Submitted May 17, 2005; submitted, revised, September 7, 2005; accepted September 21, 2005.

A brief summary of this study was presented at the AcademyHealth 2004 Annual Meeting, San Diego, Calif.

Funding support: This study was supported by the Robert Wood Johnson Foundation under grant 038690.

Acknowledgments: The authors would like to acknowledge the scholarly contributions and moral support of Robin R. Gillies, PhD.

\section{References}

1. Prepared by the Institute for Health $\varepsilon$ Aging, University of California, San Francisco, for the Robert Wood Johnson Foundation. Chronic care in America: a 21st century challenge. 1996. Available at: http://www. rwjf.org/files/publications/other/ChronicCareinAmerica.pdf. Accessed June 1, 2004

2. Anderson G, Knickman JR. Changing the chronic care system to meet people's needs. Health Aff (Millwood). 2001;20:146-160.

3. Hoffman C, Rice D, Sung HY. Persons with chronic conditions: their prevalence and costs. JAMA. 1996;276:1473-1479.

4. Institute of Medicine. Crossing the Quality Chasm: A New Health System for the 21st Century. Washington, DC: National Academy Press; 2001.

5. Casalino L, Gillies RR, Shortell SM, et al. External incentives, information technology, and organized processes to improve health care quality for patients with chronic diseases. JAMA. 2003;289:434-441.

6. McGlynn EA, Asch SM, Adams J, et al. The quality of health care delivered to adults in the United States. N Engl J Med. 2003;348:2635-2645.

7. Wagner EH, Austin BT, Von Korff M. Organizing care for patients with chronic illness. Milbank Q. 1996;74:511-544.

8. Grumbach K, Bodenheimer T. A primary care home for Americans: putting the house in order. JAMA. 2002;288:889-893.

9. Bodenheimer T, Wagner EH, Grumbach K. Improving primary care for patients with chronic illness. JAMA. 2002;288:1775-1779.

10. Bodenheimer T, Wagner EH, Grumbach K. Improving primary care for patients with chronic illness: the Chronic Care Model, Part 2. JAMA. 2002;288:1909-1914.

11. Starfield B. Primary Care: Concept, Evaluation, and Policy. New York, NY: Oxford University Press; 1992. 
12. Starfield B. Primary Care: Balancing Health Needs, Services, and Technology. New York, NY: Oxford University Press; 1998.

13. Wagner EH, Austin BT, Von Korff M. Improving outcomes in chronic illness. Manag Care Q. 1996;4:12-25.

14. Wagner EH. Chronic disease management: what will it take to improve care for chronic illness? Eff Clin Pract. 1998;1:2-4.

15. Wagner EH, Austin BT, Davis C, et al. Improving chronic illness care: translating evidence into action. Health Aff (Millwood). 2001;20:64-78.

16. Bonomi AE, Wagner EH, Glasgow RE, VonKorff M. Assessment of chronic illness care $(\mathrm{ACIC})$ : a practical tool to measure quality improvement. Health Serv Res. 2002;37:791-820.

17. Wagner EH, Davis C, Schaefer J, Von Korff M, Austin B. A survey of leading chronic disease management programs: are they consistent with the literature? Manag Care Q. 1999;7:56-66.

18. Wagner EH, Grothaus LC, Sandhu N, et al. Chronic care clinics for diabetes in primary care: a system-wide randomized trial. Diabetes Care. 2001;24:695-700

19. Wagner EH, Glasgow RE, Davis C, et al. Quality improvement in chronic illness care: a collaborative approach. Jt Comm J Qual Improv. 2001;27:63-80

20. Starfield B. Primary care and health: a cross-national comparison. JAMA. 1991;266:2268-2271.

21. Starfield B. Is primary care essential? Lancet. 1994;344:1129-1133.

22. Forrest $C B$, Starfield B. The effect of first-contact care with primary care clinicians on ambulatory health care expenditures. J Fam Pract. $1996 ; 43: 40-48$

23. Shi L, Starfield B, Politzer R, Regan J. Primary care, self-rated health, and reductions in social disparities in health. Health Serv Res. 2002:37:529-550.
24. Macinko J, Starfield B, Shi L. The contribution of primary care systems to health outcomes within Organization for Economic Cooperation and Development (OECD) countries, 1970-1998. Health Serv Res. 2003:38:831-865.

25. Baicker K, Chandra A. Medicare spending, the physician workforce, and beneficiaries' quality of care. Health Aff (Millwood). 2004; Suppl Web Exclusive:W184-W197.

26. Franks $P$, Clancy CM, Nutting PA. Gatekeeping revisited-protecting patients from overtreatment. N Engl J Med. 1992;327:424-429.

27. Greenfield S, Rogers W, Mangotich M, Carney MF, Tarlov AR. Outcomes of patients with hypertension and non-insulin dependent diabetes mellitus treated by different systems and specialties: results from the Medical Outcomes Study. JAMA. 1995;274:1436-1444.

28. Greenfield S, Nelson EC, Zubkoff M, et al. Variations in resource utilization among medical specialties and systems of care: results from the Medical Outcomes Study. JAMA. 1992;267:1624-1630.

29. Wholey DR, Christianson JB, Engberg J, Bryce C. HMO market structure and performance: 1985-1995. Health Aff (Millwood). 1997;16: 75-84.

30. Robinson JC. Physician organization in California: crisis and opportunity. Health Aff (Millwood). 2001;20:81-96.

31. Gillies RR, Shortell SM, Casalino L, Robinson JC, Rundall TG. How different is California? A U.S. comparison of physician organizations. Health Aff Web Exclus. 2003;October:W3-492-502.

32. Bodenheimer T, Wang MC, Rundall TG, et al. What are the facilitators and barriers in physician organizations' use of care management processes? Jt Comm J Qual Saf. 2004;30:505-514.

33. Rundall TG, Shortell SM, Wang MC, et al. As good as it gets? Chronic care management in nine leading US physician organisations. BMJ. 2002:325:958-961

\section{CHANGE-OF-ADDRESS FORM FAMMILY MEDICINE}

Please complete this form and mail to the following address or fax to Annals Circulation at 913-906-6080:

Annals of Family Medicine, Circulation Department, 11400 Tomahawk Creek Pkwy, Leawood, KS 66211-2672

Check if member of sponsoring organization: $\square$ AAFP $\square$ ABFM $\square$ STFM $\square$ ADFM $\square$ AFMRD $\square$ NAPCRC

ID number from label on your journal cover $\_-\ldots+-\ldots$

OLD Information (Please print.)

Name

Company (if applicable)

Address (Street plus Apt or Ste)

City

Country

Postal Code (9-digit ZIP for US)

Telephone

Fax

E-Mail
NEW Information (Please print.)

Name

Company (if applicable)

Address (Street plus Apt or Ste)

City State

Country $\quad$ Postal Code (9-digit ZIP for US)

Telephone

E-Mail 